\title{
An Inverted Fins Design Problem
}

\author{
Cheng-Hung Huang ${ }^{1}$ and Po-Wei Tung ${ }^{2}$ \\ Department of Systems and Naval Mechatronic Engineering, National Cheng Kung University, \\ Tainan, Taiwan, R.O.C.
}

\begin{abstract}
An inverted fins shape design problem in determining the optimal geometry of wavyshapes inverted fins in a two-dimensional domain, based on the desired cooling tool average temperature and cooling tool area, is examined in this work. The estimated optimal wavy-shapes inverted fins are then compared with the tree-shaped inverted fins given in [1]. It is found that the optimal wavy-shaped inverted fins have better heat dissipation performance than tree-shaped inverted fins. The commercial software CFDACE+ [2] and Levenberg-Marquardt method (LMM) [3] are utilized as the design tools in this work.
\end{abstract}

Keywords: Shape Design Problem;Wavy-Shaped Inverted Fins;Levenberg-Marquardt method 